\title{
Variables of Usability
}

\author{
James Helfrich \\ 219 Austin Building, Rexburg, ID 83460 - 1015 \\ HelfrichJ@byui.edu
}

\begin{abstract}
Though many have proposed heuristics, maximums, and guidelines to describe the various aspects of heuristic usability analysis, none offer a comprehensive variable set that is both valid and reliable. This paper proposes an eight-variable criteria-set through which usability inspections can be performed. Each variable will be compared with prior work and a precise definition through which each variable can be identified will be proposed.
\end{abstract}

Keywords: Usability engineering, usability inspection, heuristic analysis.

\section{Introduction}

Usability inspection is the process of evaluating a user interface to identify usability issues [23]. There are many methods for conducting such an inspection, including the empirical method, an expert analysis, and heuristic evaluation [5]. Empirical evaluation involves creating experiments where qualitative and quantative data is collected through observations of users. Expert analysis involves an expert giving an opinion of the design based on his or her experiences and judgment. The final method, heuristic evaluation, involves using a structured critique by means of a set of heuristics or variables [23]. This paper will focus on the third method: heuristic evaluation.

The quality of a heuristic evaluation methodology, as is true with all evaluation instruments or methodologies, is a function of two properties: validity (measuring the right thing) and reliability (the lack of error in the measurement) [8]. Though a large number of heuristic evaluation methodologies have been described in the literature [5, $9,13,18,21,23,25,27,29$ ], each is based on variable set exhibiting validity or reliability challenges. This paper will identify a new variable set based on those previously defined to allow for more valid and reliable heuristic evaluation.

\section{Variables Set}

For a variable set to be valid, it must cover all aspects of usability and nothing else. Currently there does not exist a variable set covering all the components of usability identified in the literature. For a variable set to be reliable, it needs to produce similar results with reevaluation. This requires it to be as objective as possible while not resorting to false metrics resulting in validity challenges. Stemming from these constraints and based on work of previous researchers, a new variable set is proposed: Efficiency, Learnability, Familiarity, Simplicity, Mapping, Motivation, Trust, and Visibility. 


\subsection{Efficiency}

The term and concept of Efficiency has been a focus of human factors research since 1903 [30]. Though Efficiency has been identified by many researchers [1, 29], possibly Raskin [26] put it best: "A computer shall not waste your time or require you do to more work than is strictly necessary." Efficiency is defined as the amount of effort or time required to perform a task, is an important variable in usability because it sets the limit on a user's productivity. It can be influenced by many factors, including flexibility [9, 24], directness of action [9, 23], and speed to perform the task [9, 21]. Though most measurements of Efficiency (such as time to completion, work throughput, mouse movements, processing requirements, etc.) lend themselves to absolute measures, Efficiency from the HCI perspective is fundamentally a relative measure: it compares the time or effort of a user against some norm or standard.

\subsection{Learnability}

The term "Learnability" was first applied to the context of HCI by Licklider [17] though the term can be traced to 1959 when it was originally used in the field of linguistics. Learnability has been identified in many variable sets $[4,5,16,21]$, though at present there is no generally accepted definition [12]. There are, however, reoccurring themes and ideas in the various definitions.

Learnability is the path to becoming proficient, largely a function of the number and size of inductive leaps the user must make to master the system. It is not the amount that needs to be learned (Simplicity) nor how pleasurable may be the journey (Motivation). Instead, the Learnability is a function of the difficulty of the learning process. The goal of managing Learnability is to maximize the level of proficiency achieved by the target user with as little user-effort as possible.

\subsection{Familiarity}

"Familiarity" was first applied both in term and in concept to HCI in 1983 [3] and has been identified directly as a variable of usability by many researchers $[9,21]$. There are two main components of Familiarity: Consistency and Compatibility. Consistency is a measure of how one part of a system's interface is similar to another. Compatibility, on the other hand, is how much one system's interface resembles other systems performing similar functions. Both relate to the degree in which the design resembles other designs the user may have encountered before $[9,13,16]$.

\section{$2.4 \quad$ Simplicity}

Though the concept of Simplicity has been applied to HCI and human factors from the beginning, there does not appear to be a consensus on the definition. Definitions vary from the complexity of the interface [6], the amount of distractions to the user [23], and how streamlined the interface is [22]. Simplicity, in simplest terms, is a measure of how much the user needs to know to operate the system. A more precise 
definition is the size and complexity of the minimally consistent mental model. Because perceptions of Simplicity are inherently subjective, any measurement of Simplicity must similarly have a degree of judgment built in. Also, discussions of the size and complexity of a user's mental model are intrinsically relative: it is only meaningful to compare two mental models rather than make absolute statements about one.

\subsection{Mapping}

The concept of Mapping was first described by Gibson [11], though the term entered common use in the context of usability inspections by Norman [24]. Other names have been used to describe all or part of the concept of Mapping, include Task Match [16], Directness [9], "Product Compatibility and User Compatibility" [21], and Affordance $[11,24]$. Though a large number of definitions for Mapping exist $[10,13,16$, $24,25]$, two essential components are present in all: the user's mental model and the system model. Mapping consists of cues within the design encouraging the user to form a consistent mental model of the system. While Simplicity is a measure of the size of the mental model, Mapping is about how well the interface communicates the intended model. It is important to note that the user is ultimately responsible for his or her own mental model; the best the interface can do is to encourage the user to form a consistent one and to discourage an inconsistent one. No research has been done to measure Mapping, in part due to the nature of the variable; while it is possible to accurately and completely describe a system model, it is impossible to directly measure a user's mental model. Possibly for this reason there have also been no metrics offered to quantify Mapping; indirect evidence and judgment will always be part of the equation.

\subsection{Motivation}

Motivation addresses the users' desire to use the system, encompassing both internal and external sources. Though Motivation has been described by many, Keller [14] provided the most widely acceptable framework in his ARCS (Attention, Relevance, Confidence, and Satisfaction) model. Motivation has been described through external sources (how the user is compelled to use the system) [13] and internal sources (how rewarding, aesthetically appealing, and how fun the interface is) $[2,9,16,25]$.

Some of the best usability examples are successful because their level of fun overshadows problems with Efficiency or Familiarity. Users tend to try harder, be more forgiving, and be more patient when their Motivation levels are higher [15, 31]. Because Motivation lies in the affective domain [7], it is impossible to directly measure. However, like Mapping, indirect evidence can be collected and often a certain amount of judgment is required.

\subsection{Trust}

Trust, defined by Kavonen as "the user's willingness to commit any transaction," has also been called safety $[9,13]$ and control $[9,21,25]$. Trust is the amount of 
confidence the user has when using the system, being a function of how much the system encouraging the user feel in control and how little the system behaves in an unexpected way. The variable of Trust encompasses both measures of user's perceived control over the system and avoidance of trust-compromising experiences. In both cases, poor Trust often results in poor Motivation and poor Efficiency.

\subsection{Visibility}

Visibility was first described as a HCI design constraint by [3] when building the XEROX Star system. Galitz [9] defined Visibility as "indications of status, possible actions that can be taken, and the results of actions once they are performed." Heim [13] offers a similar definition: "making the user aware of the system's components and processes, including all possible functionality and feedback from user actions."

Many researchers break Visibility into several components: reachability (any state can be reached from any other state) [5, 9], observability (visibility of data) [5], Discoverability (the probability the user will find the information or functionality he or she needs), and Precedence (the degree of prominence a desired piece of data or functionality is on a given display interface). Each definition has the common component: the degree of availability of the functionality and the data of the system to the user when he or she needs it. Thus any metric describing Visibility must include the user and his scenario.

\section{Conclusion}

Through the last two decades, there have been many heuristic evaluation frameworks proposed, including AIDE [28], MUSiC [20], PUTS [19], Dix's adaptation of Nielsen's heuristic scale [5], and QUIM [29]. It is the hope of this researcher that each of these frameworks can be improved through the adaptation of a more valid and reliable variable set. This will enable heuristic evaluation methodologies to be a more practical and useful tool in the design process, classroom, and usability lab.

\section{References}

1. Bailey, R.W.: Performance vs. preference. In: Human Factors and Ergonomics Society Annual Meeting Proceedings, pp. 282-286 (1993)

2. Barber, W., Badre, A.: Culturability: The merging of culture and usability. In: Proceedings of the 4th Conference on Human Factors \& the Web (1998)

3. Bewley, W., Roberts, T., Schroit, D., Verplank, W.: Human factors testing in the design of Xerox's 8010 "Star" office workstation In. In: CHI 1983, pp. 72-77 (1983)

4. Brown, A., Chung, L., Patterson, D.: Including the human factor in dependability benchmarks. In: Workshop on Dependability Benchmarking, pp. 9-14 (2002)

5. Dix, A., Finlay, J., Abowd, G.D., Beale, R.: Human-Computer Interaction, 3rd edn. Pearson Education Limited, Essex (2004) 
6. Dourish, P., Herrmann, T., Kellogg, W., Kunau, G.: Discussion report: Simplicity and appropriation. In: International Reports on Socio-Informatics, pp. 113-116 (2005)

7. Gagné, R.M.: Learning Hierarchies (1968)

8. Gagné, R.M., Wager, W.W., Golas, K.C., Keller, J.M.: Principles of Instructional Design, 5th edn. Thomson Learning, Belmont (2005)

9. Galitz, W.O.: The Essential Guide to User Interface Design: An Introduction to GUI Design Principles and Techniques, 3rd edn. Wiley Publishing, Inc., Indianapolis (2007)

10. Gaver, W.: Technology affordances. In: Proceedings of the CHI 1991 Conference on Human Factors in Computing Systems, pp. 79-84 (1991)

11. Gibson, J.J.: The Ecological Approach to Visual Perception. Lawrence Erlbaum (1979)

12. Grossman, T., Fitzmaurice, G., Attar, R.: A survey of software learnability: Metrics, methodologies, and guidelines. In: CHI 2009, pp. 649-658 (2009)

13. Heim, S.: The Resonant Interface. Addison-Wesley, San Francisco (2007)

14. Keller, J.M.: The systematic process of motivation design. Performance and Instruction 108 (1987)

15. Kurosu, M., et al.: Apparent usability vs. inherent usability. In: CHI 1995, pp. 292-293 (1995)

16. Leventhal, L.M., Barnes, J.A.: Usability Engineering: Process, Products, and Examples. Pearson Prentice Hall, Upper Saddle River (2008)

17. Licklider, J.C.: User-oriented interactive computer graphics. In: Proceedings of the ACM/SIGGRAPH Workshop on User-Oriented Design, Pittsburgh, PA, pp. 89-96 (1976)

18. Lidwell, W., Holden, K., Butler, J.: Universal Principles of Design. Rockport (2003)

19. Lin, H., Choong, Y., Salvendy, G.: A proposed index of usability. In: Behavior \& Information Technology, pp. 267-278 (1997)

20. Macleod, M., Bowden, R., Bevan, N., Curson, I.: The MUSiC performance method. In: Behavior and Information Technology, pp. 279-293 (1997)

21. Mayhew, D.J.: Principles and Guidelines in Software User Interface Design. Prentice-Hall, Inc., Upper Saddle River (1992)

22. Mollerup, P.: Simplicity. In: Design Research Quarterly, pp. 7-15 (2006)

23. Nielsen, J., Mack, R.L.: Usability Inspection Methods. John Wiley \& Sons (1994)

24. Nielsen, J.: Ten Usability Heuristics

(2001), http: / /www. useit.com/papers/heuristic/

25. Preece, J., Rogers, Y., Sharp, H.: Interaction Design: Beyond Human-Computer Interaction. John Wiley \& Sons, Inc., New York (2002)

26. Raskin, J.: The Humane Interface. Addison-Wesley, Reading (2000)

27. Rorres, R.J.: Practitioner's Handbook for User Interface Design and Development. Prentice-Hall, Inc., Upper Sandle River (2002)

28. Sears, A.: AIDE: A step toward metric-based interface development tools. In: UIST 1995, pp. 101-110. ACM Press, Pittsburgh (1995)

29. Seffah, A., Donyaee, M., Kline, R., Padda, H.: Usability measurement and metrics: A consolidated model. Software Quality Journal, 159-178 (2006)

30. Taylor, F.W.: Shop management. American Society of Mechanical Engineers (1903)

31. Tractinsky, N.: Aesthetics and apparent usability: Empirically assessing cultural and methodological issues. In: CHI 1997, pp. 115-121 (1997) 